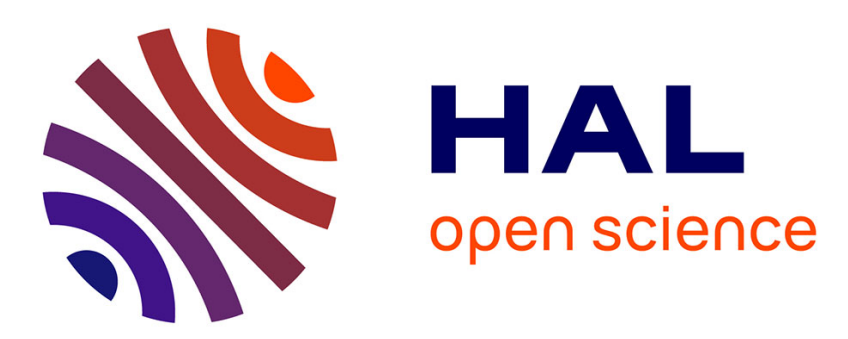

\title{
Contribution, Social networking, and the Request for Adminship process in Wikipedia
}

\author{
Romain Picot-Clémente, Cécile Bothorel, Nicolas Jullien
}

\section{To cite this version:}

Romain Picot-Clémente, Cécile Bothorel, Nicolas Jullien. Contribution, Social networking, and the Request for Adminship process in Wikipedia. OpenSym 2015: 11th International Symposium on Open Collaboration, Aug 2015, San Francisco, United States. hal-01192597

\section{HAL Id: hal-01192597 \\ https://hal.science/hal-01192597}

Submitted on 8 Sep 2015

HAL is a multi-disciplinary open access archive for the deposit and dissemination of scientific research documents, whether they are published or not. The documents may come from teaching and research institutions in France or abroad, or from public or private research centers.
L'archive ouverte pluridisciplinaire HAL, est destinée au dépôt et à la diffusion de documents scientifiques de niveau recherche, publiés ou non, émanant des établissements d'enseignement et de recherche français ou étrangers, des laboratoires publics ou privés. 


\title{
Contribution, Social networking, and the Request for Adminship process in Wikipedia
}

\author{
Romain Picot-Clémente \\ UMR CNRS 6285 Lab-STICC
}

\author{
Cécile Bothorel \\ UMR CNRS 6285 Lab-STICC
}

\author{
Nicolas Jullien \\ ICI-M@rsouin
}

\author{
Institut Mines Telecom Bretagne \\ Brest, France \\ \{Romain.PicotClemente, Cecile.Bothorel, Nicolas.Jullien\} @telecom-bretagne.eu
}

\section{INTRODUCTION}

Epistemic communities are said to be project-oriented communities of experts, evaluated on their contribution in terms of knowledge, where the main criterion for promotion is knowledge production [3]. However, [5], for Wikipedia, [7], for open source, have argued that taking responsibility is an additional step from being a regular contributor, and social interactions with peers may be an additional requirement for being promoted [6].

This work addresses this discussion by looking at the electing process of the administrators (admin) in the English Wikipedia, where exists a quite competitive process of election for the managing position called "administrator", where social connections and knowledge production skills seem to matter. From 2006-01-01 to 2007-10-01, which is our period of study, there were 1,617 RfA, with a $49.2 \%$ rate of success).

Burke and Kraut [2] proposed a model to predict RfA results $^{1}$, mainly based on counting attributes for modelling the candidate's activity, according to the criteria put forward by the Guide to RfAs ${ }^{2}$. Their model's accuracy reached $75.6 \%$. However, they did not measure the respective influence of the edits and of the social interaction on RfA results, as their measure of social influence is based on the discussion in the article pages, which can be considered as productionrelated activities more than social interaction. Neither did they separate social networking with administrators from social networking with everyone, whereas an administrator (or a bureaucrat) may be more influential than an unknown user on an RfA result [4]. This work aims at addressing these limitations. It provides more accurate model than [2] ( $78 \%$ vs $75.6 \%)$, with more simple variables, easier to extract from the raw data. It shows that beyond a required minimal number of edits, social interactions with people and

${ }^{1}$ Using the Stanford Large Network Dataset Collection, https://snap.stanford.edu/data/\#\#wikipedia, as we did, to be comparable.

${ }^{2}$ http://en.wikipedia.org/wiki/Wikipedia:GRFA

Permission to make digital or hard copies of part or all of this work for personal or classroom use is granted without fee provided that copies are not made or distributed for profit or commercial advantage and that copies bear this notice and the full citation on the first page. Copyrights for thirdparty components of this work must be honored. For all other uses, contact the Owner/Author. Copyright is held by the owner/author(s).

OpenSym August 19-21, 2015, San Francisco, USA

2015 ACM 978-1-4503-3666-6/15/08

DOI: http://dx.doi.org/10.1145/2788993.2806211 . with peers make the difference between success and failure in the RfA.

\section{MODEL}

\subsection{The variables}

\section{Revision Activities.}

We extracted the number of revisions/editions made (variable: Revision), the number of distinct pages edited (Pages) and the number of distinct categories edited (Categories), and the repartition of the revisions (Revision repartition $_{\text {) in or- }}$ der to take into account both the volume and the variety of the revisions (Gini coefficient on the number of revisions per pages).

We assumed that the talks on the articles' discussion pages were related to the revision activities: the number of distinct pages the candidates talked on (TalkPages), the total number of talks on the articles' discussion pages (PageTalks), and the Gini Coefficient fo their repartition (PageTalks repartition $_{\text {). }}$.

\section{Social Activities.}

We focused on the conversations on the users' pages to assess the impact of non-knowledge-production interactions. We created three weighted and oriented graphs: a general one, named userSN (nodes: the considered candidates and all the wikipedians); $\operatorname{admin} S N$ (nodes: the considered candidates and the (already) admins); bur $S N$ (nodes: the considered candidates and the (already) bureaucrats).

For each graph, we computed the attributes that described the characteristics of each node "candidate". They have the same name, with as suffix the name of the related graph: the degree of the node (Degree), without taking into account the orientation of edges; the number of distinct users (resp. admins, bureaucrats) to whom the candidate posted a message on their user page (outDegree), the number of distinct users (resp. admins, bureaucrats) that posted a message on the candidate's page (inDegree); the total number of messages posted (outTalksNumber) and received (inTalksNumber) by the candidate. Then, we computed multiple centrality measures on the graphs: Closeness, PageRank, and Betweenness. Finally, we computed the Gini coefficients for both the number of messages posted by the candidates (outTalks $s_{\text {repartition }}$ ), and received by them $\left(\right.$ inTalks $\left._{\text {repartition }}\right)$.

\subsection{The models}


We used the random forest algorithm [1] to predict the election, with a learning population ( $70 \%$ of our sample). Since we want to understand the contribution of the social attributes in the RfA result, we first create two predictive models, one based on the revision attributes (Model 1) and one based on the social attributes (Model 2). Then, we consider a model using all the attributes (Model 3, not presented here), and then Model 3's most relevant attributes (Model 4, which is as good as Model 3, but with less variables and a smaller variance in accuracy).

\section{RESULTS}

According to the results presented in Table 1, social and revision attributes seem to be complementary for predicting the RfA results.

\begin{tabular}{|l|c|c|c|c|c|}
\hline & Global & \multicolumn{4}{|c|}{ Confusion Matrix } \\
& Accuracy & & 0 & 1 & Accuracy \\
\hline Model 1 & & 0 & 169 & 77.5 & $68.6 \%$ \\
(Revisions) & $74 \%$ & 1 & 48 & 190 & $79.8 \%$ \\
\hline Model 2 & & 0 & 168 & 80 & $67.7 \%$ \\
(Social) & $74 \%$ & 1 & 46.5 & 192 & $80.5 \%$ \\
\hline Model 4 & & 0 & 177 & 70 & $70.6 \%$ \\
(Rev. + soc.) & $78 \%$ & 1 & 37 & 200 & $84.4 \%$ \\
\hline
\end{tabular}

Table 1: Accuracy and Confusion matrix.

The random forest method computes the average decrease of accuracy for each tree in the forest when a given attribute is not used. According to this metric, the most important attributes are Revisions, TalkPages, outDegree userSN. Table 2 details those attributes for predicting successful and unsuccessful promotions.

For each of the main 9 attributes, but the PageRank, there are significant behavioural differences between the promoted and the non-promoted candidates: the interdecile range of the probability density for the promoted candidates is smaller than the one for non-promoted candidates (the curve is flatter). This suggests that the promoted candidates behave more similarly than the non-ones, explaining why the models predict better promotion than non-promotion. The successful candidates are also more active than the unsuccessful ones (for example a candidate with a greater outDegree $_{\text {userSN }}$ is more likely to be elected).

The estimated probability of being elected according to the number of revisions (Revisions) is less than $50 \%$ beyond about 2500 revisions and is about $70 \%$ beyond 6000 revisions. There is a similar behavior pattern (probability of $50 \%$ beyond a threshold $(\mathrm{T})$ and extreme values with not enough case studies) for the following attributes: Categories $(T \approx 1700)$, TalkPages $(T \approx 130)$, outDegree userSN $(T \approx 450)$, outDegree $_{\text {adminSN }}(T \approx 17)$, inDegree userSN $(T \approx 140)$.

\begin{tabular}{|l|l|}
\hline Successful promotions & Unsuccessful promotions \\
\hline outDegree_userSN & Revisions \\
Revisions & TalkPages \\
TalkPages & inDegree_userSN \\
outDegree_adminSN & Categories \\
Categories & outDegree_adminSN \\
\hline
\end{tabular}

Table 2: The most important attributes to predict successful and unsuccessful promotions

\section{DISCUSSION}

Our results are consistent with the Guide to RfA, previous results and the theories on epistemic communities. Regarding the guide, we provide much more precise figures of how many contributions and interactions are needed to have a high probability for being elected. We show that there are quite narrow windows in terms of number of contributions and discussions, in which the chances of being elected are maximized. We dramatically simplified the measures proposed by [2] regarding the edit activities, with a better evaluation of the chances to be elected ( $78 \%$ of good prediction vs $75.6 \%$ ), while keeping the number of explanatory variables reasonably low, and easy to extract from the raw data.

As supposed for an epistemic community, the contribution in knowledge (Revision) is the first criterion to be considered as a good candidate, and a shortage of contribution is often synonymous to failure. But, once the candidates have proven their competence (production of knowledge) and their willingness to do the job (interacting with people), knowing and being known by these core members, who are the future peers, makes the difference.

There are obvious limitations to our work which will be addressed in future work: we studied one project only and with not recent data. Second, if our model is good at forecasting the elections (more than $80 \%$ of accuracy), it is not as good for the non-elections (around 70\%). Dropping the extreme cases (people who are not elected because they talked too much, maybe because they fought too much) may improve the prediction.

\section{References}

[1] L. Breiman. Random forests. Machine learning, 45(1): 5-32, 2001.

[2] M. Burke and R. Kraut. Mopping up: Modeling wikipedia promotion decisions. In Proceedings of $C S C W$ 2008, pages 27-36. ACM, 2008.

[3] P. Cohendet, F. Créplet, and O. Dupouet. Interactions between epistemic communities and communities of practice as a mechanism of creation and diffusion of knowledge. In J.-B. Zimmermann and A. Kirman, editors, Interaction and Market Structure. Springer, Londres, 2001.

[4] J. B. Lee, G. Cabunducan, F. G. Cabarle, R. Castillo, and J. A. Malinao. Uncovering the social dynamics of online elections. Journal of Universal Computer Science, 18(4):487-505, 2012.

[5] C. Pentzold. Imagining the Wikipedia community: What do Wikipedia authors mean when they write about their "community"? New Media \& Society, 13(5):704721, August 2011.

[6] F. Rullani and S. Haefliger. The periphery on stage: The intra-organizational dynamics in online communities of creation. Research Policy, 42(4):941-953, 2013.

[7] G. von Krogh, S. Haefliger, S. Spaeth, and M. W. Wallin. Carrots and Rainbows: Motivation and Social Practice in Open Source Software Development. MIS Quarterly, 36(2):649-676, 2012. 